\title{
Helical root chondrocutanuous composite graft for nasal reconstruction: Two case reports
}

\section{Mohammed Nayef AL-Bdour, Khalid Ali Mohammed El-Maaytah, Lamees Abdel-Rahim Arabiyat, Mohammed Fahed AL Shishi, Odai Musa Sayegh, Hamad Mohamed Ammar}

\author{
Department of Plastic and Reconstructive Surgery, King Hussein Medical Center, Royal Jordanian Rehabilitation Center, \\ Royal Medical Services, Amman, Jordan
}

Corresponding author: Dr. Mohammed Nayef AL-Bdour, E-mail: mbdooor@yahoo.com

\begin{abstract}
Traumatic loss of any aesthetic subunit of the nose poses a reconstructive challenge for the plastic surgeon. Different surgical techniques are discussed in the literature, ranging from primary closure to free flap reconstruction for complex defects. Due to their cylindrical layered morphology and peripheral location; columella and alar margin are difficult to reconstruct. The Helical root chondrocutanuous composite graft is a single-stage procedure that can be used to restore the lost part of these aesthetic subunit of the nose. We present 2 cases, the first case is about a 3 year old child with prolonged use of nasal CPAP in the NICU resulted in columellar necrosis, and the second case for a 28 year old female patient with history of a childhood post nasal trauma alar rim defect, both cases were reconstructed successfully with helical root chondrocutanous composite grafts. We provide a thorough explanation of the composite graft design and operative technique. Helical root chondrocutanuous composite graft can produce desirable aesthetic outcomes with minimal donor site morbidity and should be considered in patients presenting with traumatic or iatrogenic loss of the columella and alar margin.
\end{abstract}

Key words: Columella necrosis; Alar defect; Composite graft; Chondrocutanuous graft

\section{INTRODUCTION}

The fragile alar rims and columella are complex structures in which specialized and supportive skin ensures the competence of the external valves and the patency of the inlets to the nasal airways, causative factors for their loss can be post traumatic, post excisional (malignancy) and post infection.

From reconstructive standpoint; alar margin and columellar defects are more distinct than other nasal subunits by their peripheral location and cylindrical layered morphology, it's usually difficult to ensure a good aesthetic outcome provided that most of reconstructive options involve scarring in a visible area of the face.
The first description of composite grafts for nasal reconstruction dates back to Konig in 1902.

Composite grafts for nasal reconstruction have been described in many literatures especially it is used as one stage reconstruction.

\section{CASE REPORTS}

The first case is about a male child presented to our clinic with prolonged use of nasal CPAP in the NICU during neonatal period resulted in columellar necrosis (Fig. 1).

On examination there was total loss of columella and anterior nasal septum.

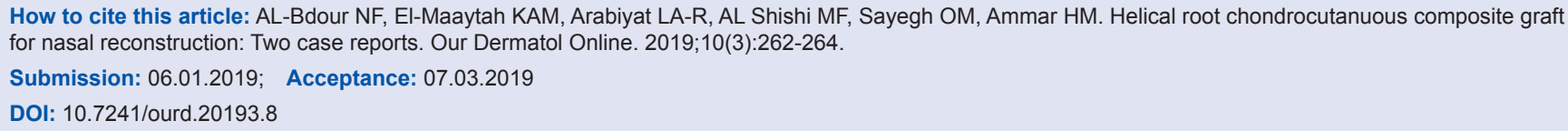


Looking at the site and size of the defect, a plan was made to reconstruct the defect in a single stage operation, using a composite chondrocutanous graft taken from the ear root of the helix (Figs. $2 \mathrm{a}-2 \mathrm{c}$ ).

The composite graft was sutured to recipient defect after recipient bed preparation, donor site was closed primarily.

The take of composite graft was adequate with good correction of defect and donor site healed completely with minimal donor site scarring (Figs. 3 and 3b).

The second case is 28 years old female patient with history of a childhood post nasal trauma left alar rim defect (Figs. $4 \mathrm{a}-4 \mathrm{c}$ ).

Also planning was to restore alar rim margin using chondrocutanous composite graft from ear,root of the helix (Figs. 5a-5c).

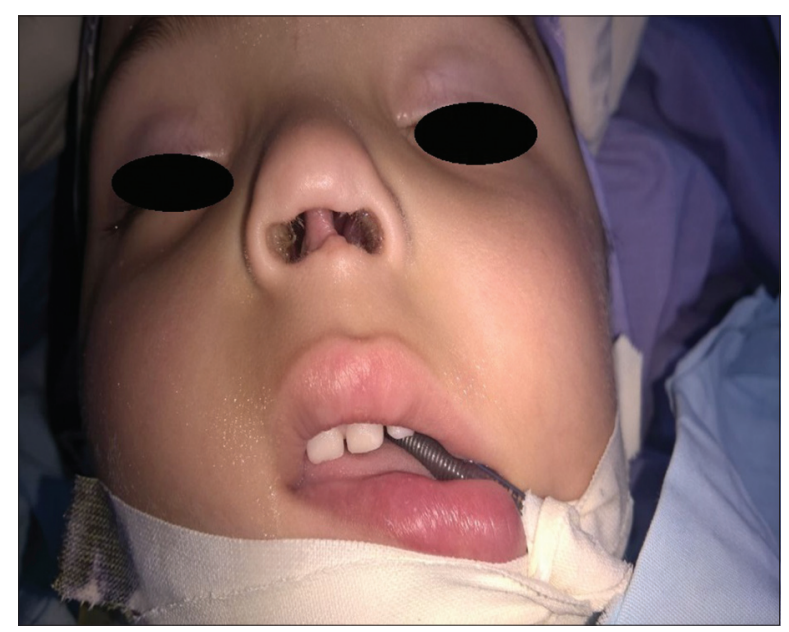

Figure 1: Columellar and anterior septal defect.

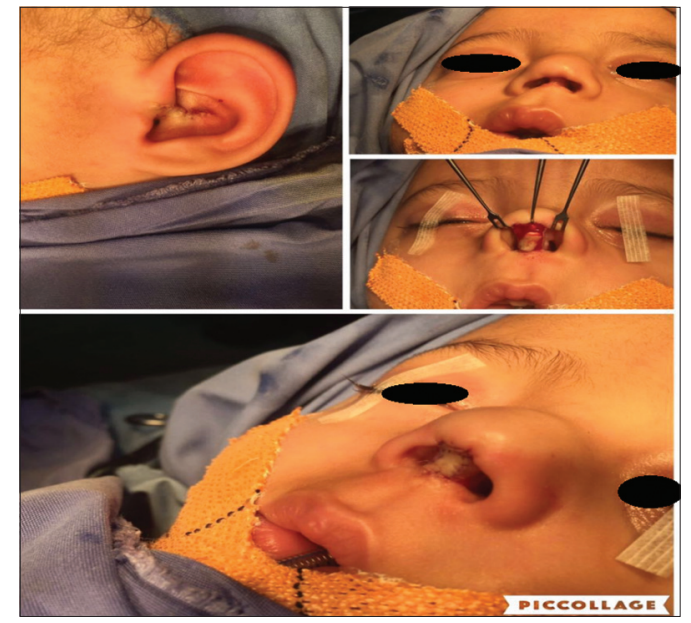

Figure 2: Composite graft from root of helix harvest and inset.
The take of composite graft was excellent and restoration of alar rim with good contour, color and texture and the donor site healed with no significant scarring (Figs 6a and 6b).

\section{DISCUSSION}

The nose is corner stone in facial appearance and whole body image, restoration of near normal appearance and function are the definitive goals for reconstruction.

The nose is composed of nine aesthetic subunits: two side walls, two ala, two soft triangles, tip, dorsum and columella. From reconstruction stand point this is very important from aesthetic subunit restoration principle [1-4].

Successful surgical strategies for nasal reconstruction are based on accurate analysis of the defect taking into consideration: the size, contour, shape, layers involved and the aesthetic subunits affected.

The reconstructive ladder in nasal defects ranges from: healing by secondary intention and primary closure to skin grafts to local and regional flaps. The peripheral

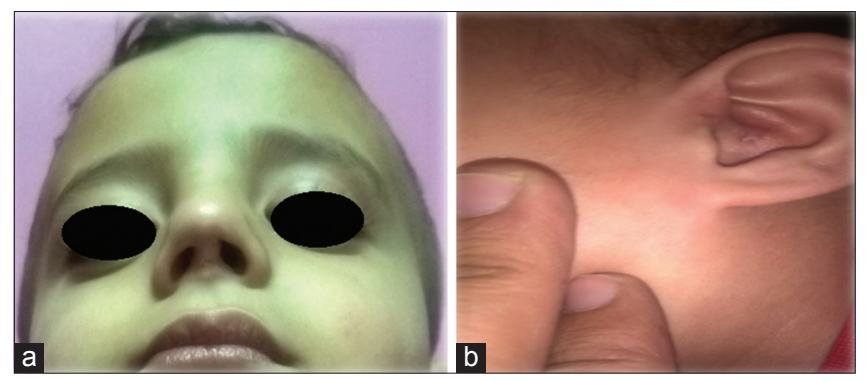

Figure 3: Five months follow up with successful aesthetic restoration of columella and minimal donor site morbidity.

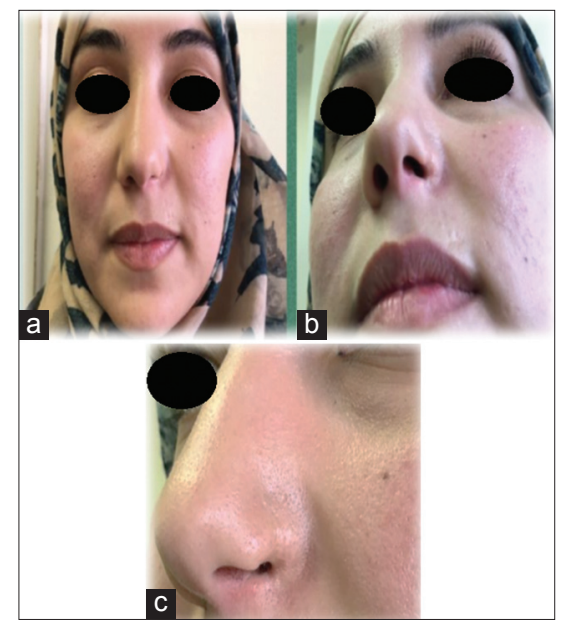

Figure 4: Post traumatic left alar rim defect. 


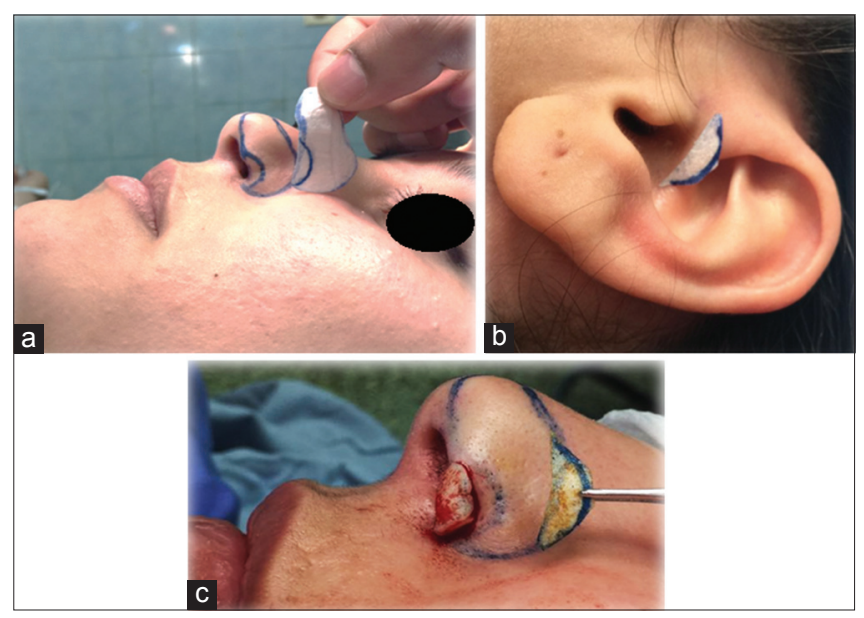

Figure 5: Using paper template from the normal ala, defect was analyzed and restored with composite graft after recipient bed preparation.
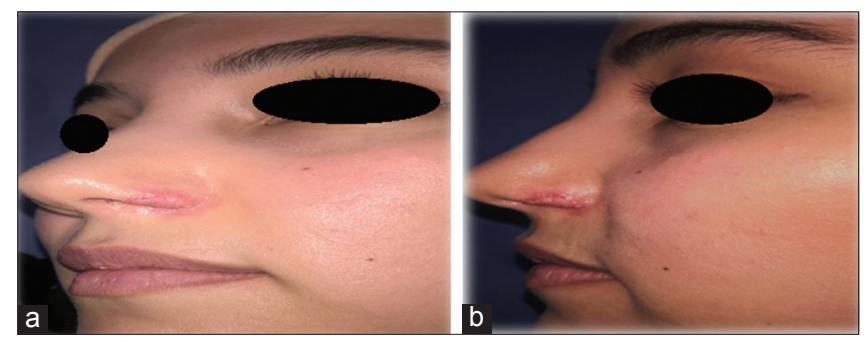

Figure 6: One month follow up showing excellent uptake of the composite graft.

location of columella and alar rim with its cylindrical layered topography and thin skin carry further burden to reconstruction [1-6].

For reconstruction of nasal columella and ala many literatures described loco regional flaps: nasal sulcus flap, forehead flap and nasolabial flaps, but all will add more scars to face and undesirable aesthetic outcomes.

Composite chondrocutanous graft was described in many literatures, grafts were harvested from helix margin concha which gives traditional wedge shaped of two skin layers separated by cartilage, in our cases report we harvested composite graft from root of helix which gives composite graft of cartilage covered by skin besides it gives better aesthetic outcomes and hidden donor site scar.

Many authors recommended that composite graft size should not exceed $10 \mathrm{~mm}$ in diameter for graft survival as if it exceeds $10 \mathrm{~mm}$ success rate decrease, composite graft with more than $15 \mathrm{~mm}$ chance of survival less than
$50 \%$, in our cases all composite graft size was less than $10 \mathrm{~mm}[1,2,3,4,7-9]$.

\section{CONCLUSION}

Helical root chondrocutanuous composite grafts can produce desirable aesthetic outcomes and should be considered in patients presenting with traumatic or iatrogenic loss of columella and alar rim.

\section{Statement of Human and Animal Rights}

All procedures followed were in accordance with the ethical standards of the responsible committee on human experimentation (institutional and national) and with the Helsinki Declaration of 1975, as revised in 2008 .

\section{Statement of Informed Consent}

Informed consent was obtained from all patients for being included in the study.

\section{REFERENCES}

1. Burget GC, Menick FJ. The subunit principle in nasal reconstruction. Plast Reconstr Surg. 1985;76:239-247.

2. Menick FJ. Principles and planning in nasal and facial reconstruction: making a normal face. Plast Reconstr Surg. 2016;137:1033e-47e.

3. Menick FJ. Nasal reconstruction. Plast Reconstr Surg. 2010;125:138e-50e.

4. Menick FJ. Practical details of nasal reconstruction. Plast Reconstr Surg. 2013;131:613e-30e.

5. Moolenburgh SE, McLennan L, Levendag PC, Munte K, Scholtemeijer M, Hofer SO, et al. Nasal reconstruction after malignant tumor resection: an algorithm for treatment. Plast Reconstr Surg. 2010;126:97-105.

6. Al-Bdour M, Al-Khateeb Mr. Reconstruction of nasal skin defects following excision of basal cell carcinoma. N Dermatol Online. 2011;3:125-9.

7. Chang CS, Swanson JW, Wilson A, Low DW, Bartlett SP. Columellar reconstruction following nasal continuous positive airway pressure injury. Plast Reconstr Surg. 2018;141:99e-102e.

8. Ahuja RB, Gupta R, Chatterjee P, Shrivastava P. Securing aesthetic outcomes for composite grafts to alar margin and columellar defects: A long term experience. Indian J Plast Surg. 2014;47:333-9.

9. Chopra S, Bangad S, Kelgaonkar TU, Somani SS, Ingle SB. Single stage reconstruction of alar rim defect using auricular composite graft: a case report. Indian J Med Case Rep. 2012;1:27-9.

Copyright by Mohammed Nayef AL-Bdour, et al. This is an open-access article distributed under the terms of the Creative Commons Attribution License, which permits unrestricted use, distribution, and reproduction in any medium, provided the original author and source are credited.

Source of Support: Nil, Conflict of Interest: None declared. 